\title{
Fire extinguishing efficiency of hydrocarbon and fluorinated film-forming foaming agent
}

\author{
Nikolay Vlasov ${ }^{1}$ and Artem Melnikov ${ }^{1, *}$ \\ ${ }^{1}$ Moscow State University of Civil Engineering, Yaroslavskoeshosse 26, Moscow, 129337, Russia
}

\begin{abstract}
This article analyzes the fire extinguishing efficiency of hydrocarbon and fluorinated film-forming foaming agent. It was revealed that fluorinated blowing agents have a number of significant advantages over hydrocarbon. The main ones are: ensuring inertness when feeding from foam of various heights and distances, long-term prevention of reignition, extinguished petroleum product, the possibility of extinguishing hydrocarbon flames by supplying foam to the base of the tank, directly into the fuel layer
\end{abstract}

\section{Introduction}

Fire protection of tanks holding oil and its products relies on a combination system where the foam is served at the same time to the tank's base and to the annular space between the tank's roof and wall [1-4].

A serious disadvantage of all existing methods of fire extinguishing by serving foam to the tank's base, is its low efficiency when fighting fires inside tank pontoons or floating roofs. As the pontoon is partly flooded, the foam served from below tends to accumulate in the tank's one half but not to flow to the other half that is open on top. If a burst of the vapor-air mix blows the mounted foam generators off, the fire becomes practically unstoppable. Such cases have to use extra quantities of foaming agent [5-7].

Because estimated intensity of foam injection from the top can extinguish the fire only in the narrow gap between the floating roof and the wall, then if the pontoon or floating roof is partly flooded, it becomes impossible to extinguish fire over the entire exposed surface. Quantity of foam served to the tank's base is sufficient to extinguish fire on the entire area, but the tilted roof or pontoon blocks entry of foam into the partitioned area of the oil product surface. This creates a problem with using foam in the subsurface extinguishing system.

Due to the issue of environmental pollution, in the last decade there have been calls to replace fluorine containing foam agents with hydrocarbon foam agents that easily degrade after use.

Fluorinated or film forming foam agents were introduced because of certain requirements that cannot be met using foam obtained from hydrocarbon foam agents.

Primarily, this is due to dramatically reduced extinguishing efficiency when foam is applied onto the burning surface of petroleum product from a large distance or from a large

\footnotetext{
*Corresponding author: artem1melnikov@gmail.com
} 
height. Foam generated with hydrocarbon foam agents is mixed with the petroleum product when it is submerged in it due to falling from a large height. Foam behaves this way because the surface tension of foam agent water solution is high. This results in hydrocarbon spreading over foam films, and the fuel penetrating into foam structure. Contamination by hydrocarbon dramatically reduces the isolating capacity of foam, and the foam itself supports combustion.

Most often, a fire begins with explosion of vapor-air mixture that has formed inside the tank. That is why foam chambers installed in the tank top ring are destroyed, and the tank roof is partially submerged into the burning petroleum product.

It is problematic to find a way of applying foam into the semi-closed space, i.e. the "pocket" where combustion continues although adjacent surface on the other side of partition wall is sealed off by foam. It was proposed to apply foam into the burning "pocket" from below, under the petroleum product layer.

When fluorine containing foam agents became available, the task of ensuring a long time period before petroleum product re-ignites after the fire is extinguished, was completed. The foam was not only efficient with low expansion ratio and when feed from a large distance, but also gave off water solution that naturally spread over the gasoline surface and prevented fuel evaporation.

It has been noticed at real fires that foam produced from hydrocarbon foam agent quickly disintegrated after extinguishing the fire in the tank. However, metal structures that became incandescent during the fire remained heated to a high temperature. After extinguishing and rapid disintegration of foam, petroleum product vapor emerged again and, after mixing with air, formed a combustible mixture. Because an ignition source was available (incandescent metal parts that had formed out of the destroyed roof), petroleum product in the tank ignited again. The fire was combined with an explosion resulting in partial or complete destruction of the tank and spillage of petroleum product within the tank bunding. Fire conditions became catastrophic because the fire spread to adjacent tanks.

Thus, the reason fluorine containing film forming foam agents emerged and were quickly implemented was the need to solve fire-fighting problems: ensure inertness when submerged into petroleum product if the foam is applied from large heights and distances, capacity to extinguish fire inside a tank, foam application to the tank base and ensuring a long period of time before combustible liquid re-ignition after the fire is extinguished.

Foam generated with hydrocarbon foam agent cannot meet any of the above-mentioned requirements.

Completed analysis demonstrates that using film forming foam agents to extinguish petroleum product fires during emergency spills and fires in tanks is an essential prerequisite to ensure efficiency and safety of fire-fighting personnel who participate in fire suppression.

The objective of this study is to demonstrate by experiment that foam obtained from water solutions of fluorine containing film forming foam agents is superior to hydrocarbon agents in terms of its capability to solve the above-mentioned problems related to suppressing petroleum product fires.

Foam was applied directly onto the burning surface and into the petroleum product layer. Gasoline and n-heptane were used as the combustible liquid which ensures that obtained results were reproducible [5-9].

\section{Materials and Methods}

The tests were carried out on bedstead described in GOST R 53280.2-2010 and GOST R 50588-2012. The dependence of the specific consumption and extinction time on the foam 
application rate was determined. The foam was applied directly to the burning surface. Nheptane was used as a flammable liquid that allowed obtaining reproducible results [1-4].

Preliminary measurement of interracial tension of the working solutions at the heptane junction was carried out to confirm the nature of the foamer. The ring method was used to measure the interracial tension of foamer solutions. These tests confirmed the nature of foamers' surfactant base.

The spreading on heptane coefficient for film-forming foamers should be greater than zero, and the interracial tension should be lower than for heptane $-17 \mathrm{mN} / \mathrm{m}$. Solutions of hydrocarbon SAS have interracial tension around $30 \mathrm{mN} / \mathrm{m}$ that is noticeably higher than that of heptane [5-8].

The spreading coefficient of the aqueous-based solution on heptane $-K_{10}$ and of heptane on the solution $-\mathrm{K}_{01}$ was calculated by the following relationships [1-2]:

$$
\begin{aligned}
& K_{10}=\sigma_{0}-\left(\sigma_{10}+\sigma_{1}\right) \\
& K_{01}=\sigma_{1}-\left(\sigma_{10}+\sigma_{0}\right)
\end{aligned}
$$

Where $\sigma_{0}$ - is the interracial tension of heptane, $\mathrm{mN} / \mathrm{m} ; \sigma_{10}$ - is interfacial tension at solution-heptane junction, $\mathrm{mN} / \mathrm{m} ; \sigma_{1}$ - is the interracial tension of an aqueous-based at solution-air junction, $\mathrm{mN} / \mathrm{m}$.

\section{Results and Discussion}

Tests were completed using the experimental setup described in other works, similar to the setup used for comparative evaluation of foam agent extinguishing efficiency for certification purposes. The dependence of specific consumption and extinguishing time from foam application rate was determined in a broad range of foam application rates.

The results of comparative foam extinguishing efficiency tests obtained with hydrocarbon and fluorinated foam agent are shown in Fig. 1.

Judging from the foam forming solution optimum application rate value, foams from fluorinated foam agent are much more efficient than hydrocarbon foams. Optimum foam application rate with hydrocarbon foam agents is $0.075 \mathrm{~kg} /\left(\mathrm{m}^{2} \mathrm{~s}\right)$, while it is $0.035 \mathrm{~kg} /\left(\mathrm{m}^{2}\right.$ $\mathrm{s})$ for the fluorinated agent. Minimum specific consumption with hydrocarbon foam agents is $2.2 \mathrm{~kg} / \mathrm{m}^{2}$, while it is $0.9 \mathrm{~kg} / \mathrm{m}^{2}$ for the fluorinated agent. Using a fluorine containing foam agent is also preferable when foam is applied onto the burning surface. The superiority of fluorinated foams was most dramatically demonstrated when foam was applied from a large height.

The obtained result can be explained based on surface tensions isotherm lines: water solutions of fluorinated foam agent have a positive value of spreading coefficient over heptane, while in the system of hydrocarbon foam agent water solutions on the boundary with heptane, it is heptane over water solutions that has a positive value of spreading coefficient.

When hydrocarbon foam comes into contact with heptane, the fuel wets foam films and spreads over them resulting in contact disintegration. Upon contact with heptane, foam from fluorinated foam agent naturally forms a water film on the hydrocarbon surface preventing its evaporation [10-12]. 


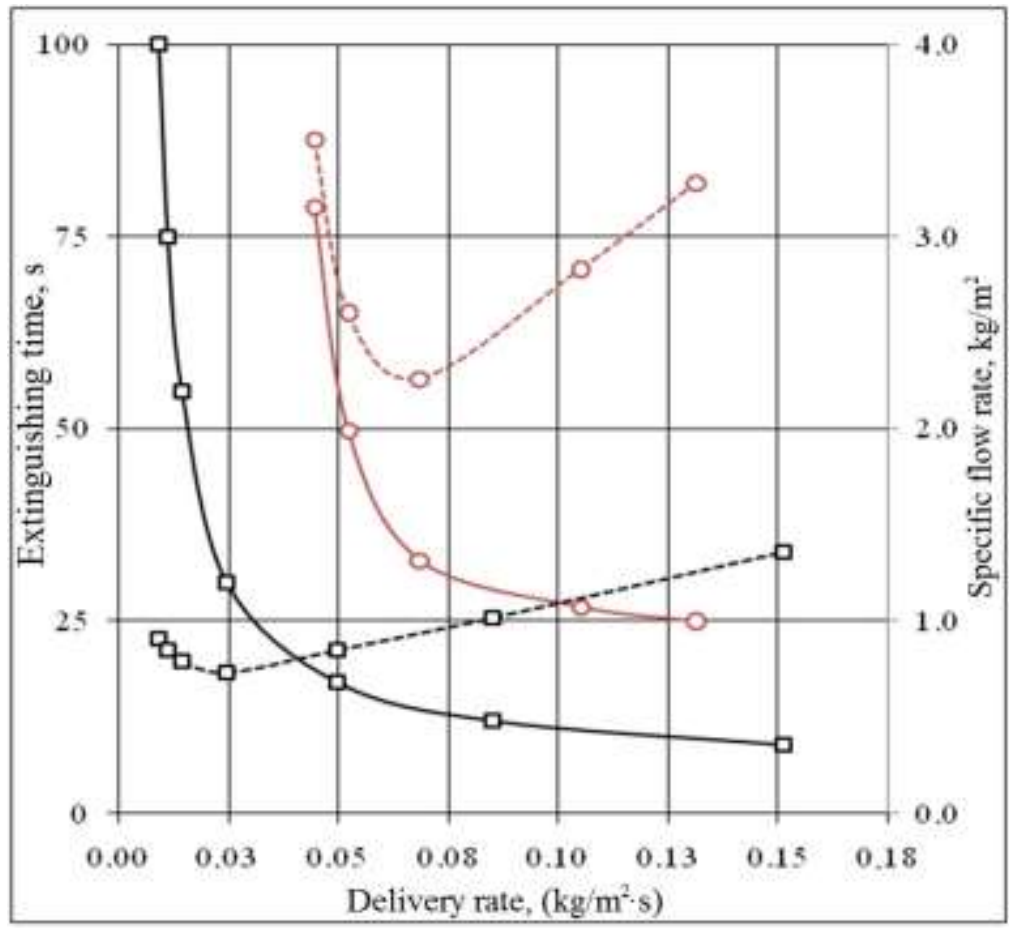

Fig. 1. Comparative foam extinguishing efficiency tests obtained with hydrocarbon and fluorinated foam agent.

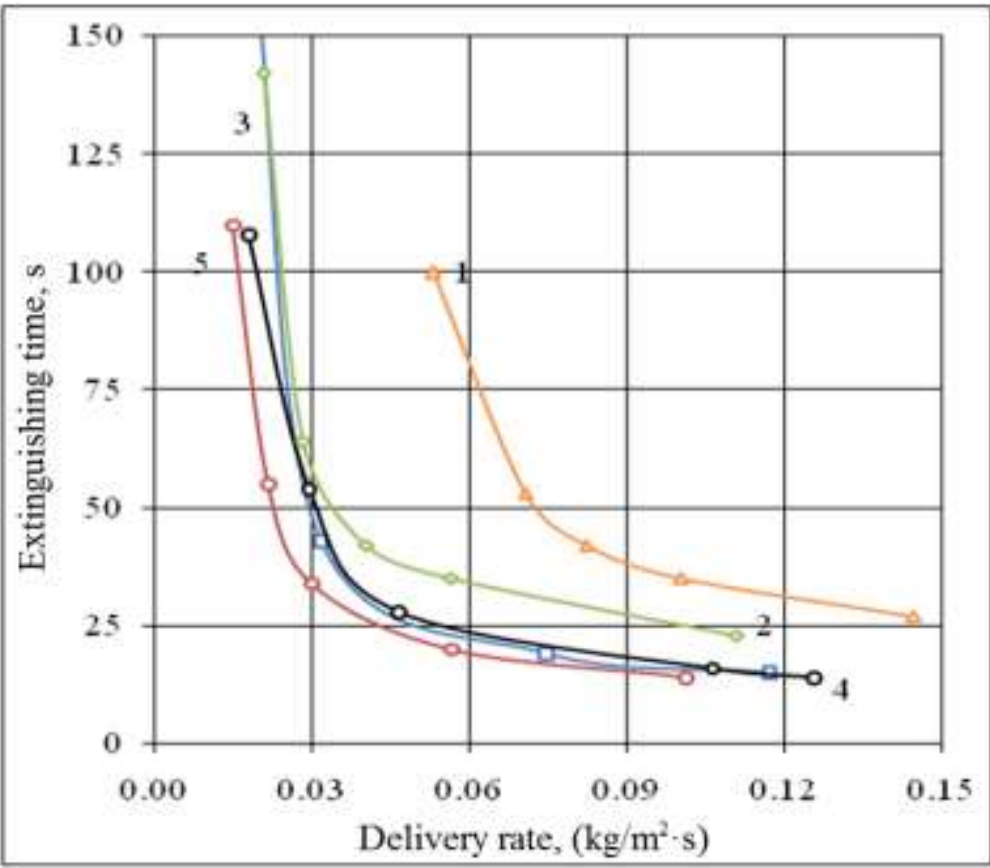

Fig. 2. Dependence between heptane extinguishing time and foam application rate for foam generated from working solutions with different spreading coefficients: $1 . \mathrm{K}_{\mathrm{R} / \mathrm{G}}=-1.0 \mathrm{mN} / \mathrm{m} ; 2 . \mathrm{K}_{\mathrm{R} / \mathrm{G}}=-0.5$ $\mathrm{mN} / \mathrm{m} ; 3 . \mathrm{K}_{\mathrm{R} / \mathrm{G}}=0.5 \mathrm{mN} / \mathrm{m} ; 4 . \mathrm{K}_{\mathrm{R} / \mathrm{G}}=1.0 \mathrm{mN} / \mathrm{m} ; 5 . \mathrm{K}_{\mathrm{R} / \mathrm{G}}=1.3 \mathrm{mN} / \mathrm{m}$. 
Measurement results of foam agent water solutions surface activity demonstrate that hydrocarbon foam agents may not be used for subsurface foam injection into burning heptane, as heptane will spread across foam films, destroying the foam and mixing with it while it is rising to the surface.

Fluorinated foam agent test with different spreading coefficient values during fire suppression by foam application to the tank base is shown in Fig. 2.

The test results demonstrate that for efficient extinguishing not only a low surface tension of water solution but also a positive spreading coefficient value are required.

The higher the spreading coefficient value is, the more efficient is the foam in extinguishing petroleum products [13-17].

Foam insulating capacity was determined in a range environment and on laboratory setup. Fragment softesting are shown in Fig. 3.

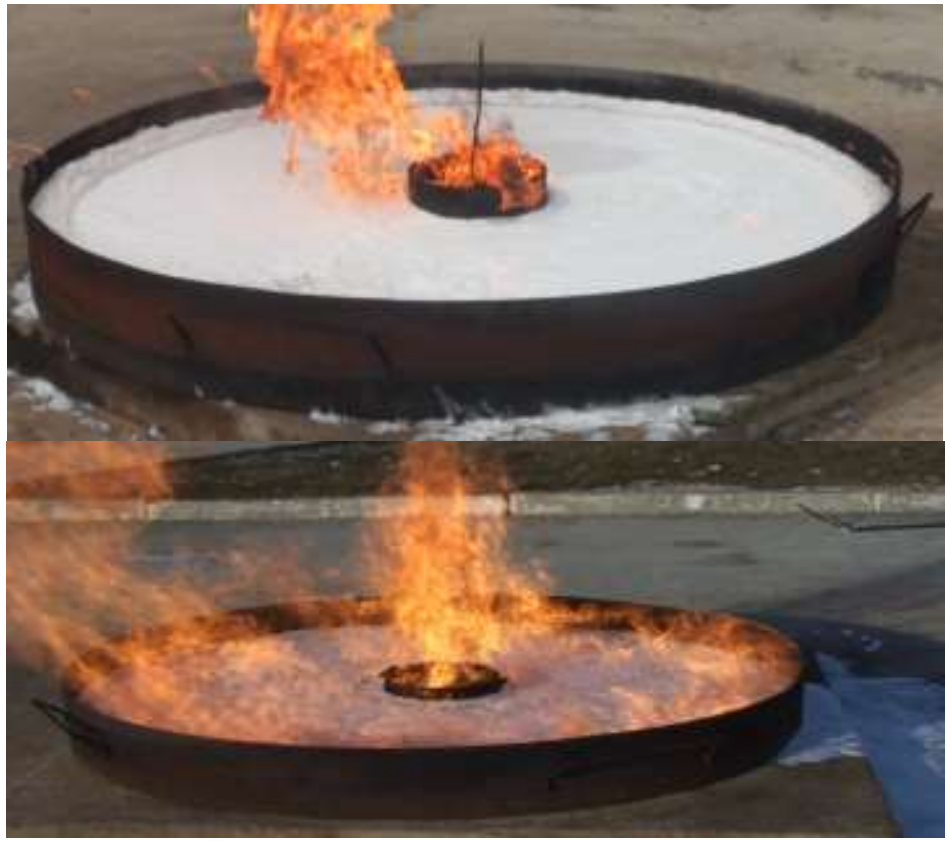

Fig. 3. Foam isolating power being lost.

Range tests of protective power duration for foam obtained from solutions with a positive coefficient of spreading over petroleum product provided results in the range of 7 to 10 minutes. During tests, a gasoline burner was placed in a tray, with the burner being ignited simultaneously with fuel in the tray.

Experiment results (Table 1) reveal that the period of heptane ignition under the foam layer is closely related to the ratio of solution and heptane spreading coefficients.

Table 1. The results of the tests of ignition of the heptane from under the foam layer.

\begin{tabular}{|l|c|c|c|c|}
\hline \multicolumn{1}{|c|}{ Constituent } & $\begin{array}{c}\text { First } \\
0<\mathrm{K}_{01}>\mathrm{K}_{10}\end{array}$ & $\begin{array}{c}\text { Second } \\
0>\mathrm{K}_{01}>\mathrm{K}_{10}\end{array}$ & $\begin{array}{c}\text { Third } \\
0>\mathrm{K}_{10}>\mathrm{K}_{01}\end{array}$ & $\begin{array}{c}\text { Fourth } \\
0<\mathrm{K}_{10}>\mathrm{K}_{01}\end{array}$ \\
\hline $\begin{array}{l}\text { Time of ignition } \\
\text { of heptane } \\
\text { under foam, s. }\end{array}$ & instantly & instantly & $15-30$ & $360-420$ \\
\hline
\end{tabular}

Foam isolating capacity is defined by spreading coefficient value ratios of fluorinated foam agent water solution spreading over heptane $\left(\mathrm{K}_{10}\right)$ and of heptane spreading over the solution $\left(\mathrm{K}_{01}\right)$. 


\section{Conclusions}

Obtained results demonstrate that foam agents with fluorinated stabilizers help achieve the required objective: ensure inertness for application from different heights, prevent reignition for a long period of time, and suppress petroleum product fire by foam application to the tank base, directly into the fuel layer.

\section{References}

1. S. Korzeniowski, T. Cortina, Industrial Fire Journal 4, 18-20 (2008)

2. T. Cortina, Industrial Fire Journal 6, 70-75 (2007)

3. M. Pabon, J.M. Corpart, Journal of Fluorine Chemistry 114-2, 149-156 (2002) DOI: 10.1016/S0022-1139(02)00038-6

4. D.A. Korolchenko, A.F. Sharovarnikov, A.V. Byakov, Advanced Materials Research 1073-1076, 2353-2357 (2015)

5. D.A. Korolchenko, E.N. Degaev, A.F. Sharovarnikov, 2nd International Conference on Material Engineering and Application (ICMEA 2015), 17-22 (2015)

6. I.M. Shaluf, S.A. Abdullah, Journal of Loss Prevention in the Process Industries 24-1, 1-7 (2011) DOI: 10.1016/j.jlp.2010.06.007

7. H. Yinsheng, W. Zhang, D. Xiaojing, Z. Yu, Procedia Engineering 45, 649-654 (2012) DOI: 10.1016/j.proeng.2012.08.217

8. D. Korolchenko, A. Tusnin, S. Trushina, A. Korolchenko, International Journal of Applied Engineering Research 10-21, 42541-42548 (2015)

9. T.H. Schaefer, B.Z. Dlugogorski, E.M. Kennedy, Fire Technology 44-3, 297-309 (2007) DOI: 10.1007/s10694-007-0030-8

10. D.A. Korolchenko, A.F. Sharovarnikov, E.N. Degaev, IV International Scientific Conference of Young Scientists and Specialists: Problems Of Technosphere Safety, 24-28 (2015)

11. M.J. Kennedy, M.W. Conroy, J.A. Dougherty, N. Otto, B.A. Williams, R. Ananth, J.W. Fleming, Physicochemical and Engineering Aspects 470, 268-279 (2015) DOI: 10.1016/j.colsurfa.2015.01.062

12. D.A. Korolchenko, A.F. Sharovarnikov, E.N. Degaev, Fire and Explosion Safety 24-2, 67-70 (2015) DOI: 10.18322/PVB.2015.24.02.67-70

13. Z. Qinglin, W. Lu, B. Yixing, X. Dajun, Z. Huiqiang, Q. Peifang, Journal of Hazardous Materials 287, 87-92 (2015) DOI: 10.1016/j.jhazmat.2015.01.017

14. D.A. Korolchenko, A.F. Sharovarnikov, A.V. Lyapin, Fire and Explosion Safety 23-6, 76-80 (2014) DOI: 10.18322/PVB.2014.23.06.76-80

15. A.F. Sharovarnikov, D.A. Korol'chenko, Applied Mechanics and Materials 475-476, 1344-1350 (2014)

16. D. Korolchenko, S. Voevoda, MATEC Web of Conferences 86 (2016), DOI: 10.1051/matecconf/20168604056

17. D. Korolchenko, S. Voevoda, MATEC Web of Conferences 86 (2016) DOI: $10.1051 /$ matecconf $/ 20168604038$

18. O.M. Smirnova, International Journal of Civil Engineering and Technology, 9(10), 1991-2000 (2018) 